SHORT REPORT

\title{
Absence of BRAF mutations in UV-protected mucosal melanomas
}

\author{
R H Edwards, M R Ward, H Wu, C A Medina, M S Brose, P Volpe, S Nussen-Lee, H M Haupt, \\ A M Martin, M Herlyn, S R Lessin, B L Weber
}

J Med Genet 2004;41:270-272. doi: 10.1136/jmg.2003.016667

Background: Mutations in BRAF have recently been identified in a significant percentage of primary and metastatic cutaneous malignant melanomas. As ultraviolet (UV) exposure may play a role in the development of cutaneous melanoma lesions with BRAF mutations, BRAF mutation frequency in melanomas arising in sites protected from sun exposure may be lower than those from sun-exposed areas. Thus, we determined the BRAF mutation frequency in a panel of 13 mucosal melanomas and compared those data with data from all currently published series of cutaneous melanomas.

Methods: BRAF exon 15 DNA from 13 archival primary mucosal melanomas (eight vulvar, four anorectal, and one laryngeal) was sequenced using intron-based primers. As archival DNA occasionally produces poor-quality template, results were confirmed with a TspRI restriction fragment length polymorphism (RFLP) that distinguishes wild-type $B R A F$ from the common mutant form V599E. A binomial test was used to compare the mutation frequency in the mucosal melanomas with the published mutation frequency in cutaneous melanomas.

Results: None of the 13 mucosal melanomas in this series had an exon 15 BRAF mutation, as compared to $54 / 165$ (33\%) primary cutaneous melanomas with $B R A F$ mutations in a compilation of all current published studies $(p=0.006)$.

Discussion: These data suggest that UV exposure, plays a role in the genesis of BRAF mutations in cutaneous melanoma, despite the absence of the characteristic $C>T$ or $\mathrm{CC}>\pi$ mutation signature associated with UV exposure, and suggests mechanisms other than pyrimidine dimer formation are important in UV-induced mutagenesis.

C utaneous malignant melanoma is a lethal form of skin cancer that is epidemiologically linked to solar UV exposure (reviewed in Gilchrest et al ${ }^{1}$ ). Recently, oncogenic mutations in the DNA sequence encoding the kinase domain of BRAF have been identified in the majority of primary cell lines derived from cutaneous melanomas. ${ }^{23}$ The observation that about $90 \%$ of these mutations in melanomas are due to a recurrent single nucleotide substitution (T1796A; V599E) ${ }^{23}$ raises the possibility that a specific environmental exposure contributes to the genesis of this mutation. However, the common T1796A BRAF mutation is not a characteristic UV signature mutation. UV exposure causes DNA damage via two distinct mutational mechanisms. Cyclobutane pyrimidine dimers (CPD) and 6-4 photoproducts are precursors to the $\mathrm{C} / \mathrm{T}$ and $\mathrm{CC} / \mathrm{TT}$ transitions that are the classic "UV signature" mutations. ${ }^{4} \mathrm{UV}$ exposure also causes oxidative damage via generation of oxygen free radicals, which in turn can lead to replicative errors and, ultimately, to base substitutions. ${ }^{45}$ In order to evaluate the role of UV exposure in the genesis of the T1796A BRAF mutation in cutaneous melanoma, we examined a series of melanomas arising in sites protected from sun exposure and compared our results with the published frequencies of BRAF mutations in cutaneous melanoma.

\section{METHODS}

\section{Tumour specimens}

Tissue blocks for 13 formalin-fixed paraffin-embedded mucosal melanomas (12 primary, one local recurrence), comprised of eight vulvar, four anorectal, and one laryngeal lesion, were retrieved from the Surgical Pathology archives of the Fox Chase Cancer Center and Pennsylvania Hospital under an IRB-approved protocol. The original histopathology data for each case were obtained and haematoxylin and eosin stained sections from all tumours were reviewed by a surgical pathologist (RHE).

\section{DNA extraction}

Tumour tissue was manually microdissected from surrounding normal tissue using $5 \times 5 \mu \mathrm{m}$ sections that were first stained using a modified H\&E protocol. In sequential order, the steps for this protocol were incubation in: xylene $\times 5 \min \times 2$, $100 \%$ ethanol $\times 30 \mathrm{~s} \times 2,95 \%$ ethanol $\times 30 \mathrm{~s}, 80 \%$ ethanol $\times 30 \mathrm{~s}$, $\mathrm{dd}_{2} \mathrm{O} \times 30 \mathrm{~s}$, Harris' modified haematoxylin $\times 30 \mathrm{~s}, \mathrm{ddH}_{2} \mathrm{O} \times 30 \mathrm{~s}$, ammonium hydroxide $\times 30 \mathrm{~s}, 80 \%$ ethanol $\times 30 \mathrm{~s}, 95 \%$ ethanol $\times 30 \mathrm{~s}$, eosin $\mathrm{Y} \times 30 \mathrm{~s}, 95 \%$ ethanol $\times 30 \mathrm{~s} \times 2,100 \%$ ethanol $\times 30 \mathrm{~s}$, and xylene $\times 5$ min. Slides were air-dried then placed in a vacuum dessicator for a minimum of $2 \mathrm{~h}$ to ensure complete dehydration of tissue. DNA extractions were performed using the QIAquick DNA Mini Kit (Qiagen, Valencia, CA) according to the manufacturer's protocol with one modification: during microdissection of H\&E stained sections, tissue was placed directly into Qiagen ATL buffer for proteinase $\mathrm{K}$ digestion.

\section{Mutation detection}

As archival material may yield poor quality DNA in some cases, mutation detection was performed by two independent methods. First, BRAF exon 15 was amplified by polymerase chain reaction (PCR) using previously published primers: $B R A F$ exon 15F (forward): TCATAATGCTTGCTCTGATAGGA, BRAF exon 15R (reverse): GGCCAAAAATTTAATCAGTGGA. The components of the PCR reaction mix were: $1 \times$ GeneAmp PCR Buffer II (Applied Biosystems, Foster City, CA), 2 mM $\mathrm{MgCl}_{2}, 250 \mu \mathrm{M}$ dNTPs, $1 \mu \mathrm{M}$ primers, $2.5 \mathrm{U}$ AmpliTaq Gold DNA Polymerase (Applied Biosystems, Foster City, CA), 5\%

Abbreviations: CPD, cyclobutane pyrimidine dimers; RFLP, restriction fragment length polymorphism; UV, ultraviolet 
DMSO, and $3 \mu \mathrm{l}$ DNA template in a total reaction volume of $50 \mu$ l. PCR cycling conditions were: $95^{\circ} \mathrm{C} \times 5 \mathrm{~min}, 33$ cycles of denaturation at $95^{\circ} \mathrm{C} \times 1 \mathrm{~min}$, annealing at $59^{\circ} \mathrm{C} \times 30 \mathrm{~s}$, and extension at $72^{\circ} \mathrm{C} \times 2$ min with a final extension at $72^{\circ} \mathrm{C} \times 10 \mathrm{~min}$. PCR products were gel-purified using the QIAquick Gel Extraction Kit (Qiagen, Valencia, CA) and directly sequenced using BRAF exon 15F. Sequencing reactions were analysed on an ABI 3100 Genetic Analyzer (Applied Biosystems, Foster City, CA) using software supplied by the manufacturer.

Results from direct sequencing were confirmed independently using restriction fragment length polymorphism (RFLP) analysis by digestion with TspRI. For the restriction digest, DNAs from the mucosal melanomas were PCRamplified using a hemi-nested PCR protocol. Primers for the first round of PCR were: BRAF exon $15 \mathrm{~N}-\mathrm{F}$ (forward): TTATTGACTCTAAGAGGAAAGATGAAG and BRAF exon 15N$\mathrm{R}$ (reverse): TGATTTTTGTGAATACTGGGAAC. The second round of amplification was performed using the same forward primer (BRAF exon $15 \mathrm{~N}-\mathrm{F}$ ) and the reverse sequencing primer (BRAF exon 15R). The reaction mix for the first round of PCR contained $1 \times$ PCR Reaction Buffer (Roche Applied Sciences, Indianapolis, IN), $2 \mathrm{mM} \mathrm{MgCl}_{2}, 250 \mu \mathrm{M}$ dNTPs, $1 \mu \mathrm{M}$ primers, $1 \mathrm{U}$ Taq DNA Polymerase (Roche Applied Sciences, Indianapolis, IN), 5\% DMSO, and $150 \mathrm{ng}$ of DNA in a total reaction volume of $50 \mu \mathrm{l}$. The second round of PCR utilised $2 \mu \mathrm{l}$ of PCR product from the first round of PCR as template in $2.5 \mathrm{mM} \mathrm{MgCl} 2$. All other components were identical to those used in the first round. PCR cycling conditions were: $95^{\circ} \mathrm{C} \times 5 \mathrm{~min}, 32$ cycles of denaturation at $95^{\circ} \mathrm{C} \times 1 \mathrm{~min}$, annealing at $57^{\circ} \mathrm{C} \times 2 \mathrm{~min}$ and extension at $72^{\circ} \mathrm{C} \times 2$ min with a final extension at $72^{\circ} \mathrm{C} \times 10 \mathrm{~min}$. Secondround PCR products were purified with the QIAquick PCR Purification Kit (Qiagen, Valencia, CA) and digested with TspRI in NEB Buffer 4 (New England Biolabs, Beverly, MA) at $65^{\circ} \mathrm{C} \times 24 \mathrm{~h}$. Digested and undigested products were analysed on a $12 \%$ polyacrylamide gel and visualised with ethidium bromide staining. Wild-type exon 15 BRAF DNA is completely digested by the enzyme, yielding three DNA fragments $(214,87,12 \mathrm{bp})$, however, one of two TspRI sites present in the wild-type PCR product is eliminated by the common V599E mutation, as well as by the less common V599D, V599R, and V599K mutations. Thus a heterozygous mutant template produces four fragments $(301,214,87$, $12 \mathrm{bp})$ and a hemizygous mutant template produces two fragments (301, $12 \mathrm{bp})$.

\section{Statistical analysis}

The frequency of BRAF mutations in our series of mucosal melanomas was compared with the cumulative published frequency of BRAF mutations in primary cutaneous malignant melanomas. A binomial test was used to determine the likelihood that the mutation frequency we observed between these two series occurred by chance alone, under the null hypothesis that the mutation frequency in mucosal melanomas is the same as that estimated from published series of cutaneous melanomas.

\section{RESULTS}

Using a combination of direct sequencing (12/13 samples) and TspRI RFLP analysis (13/13 samples), we did not identify any exon 15 BRAF mutations in this series of mucosal melanomas (0/13). Representative results of the RFLP analysis are shown in figure 1 . This result represents a highly significantly different BRAF exon 15 mutation prevalence in mucosal melanomas as compared to the cumulative exon 15 $B R A F$ mutation frequency published for primary cutaneous melanoma $(54 / 165 ; 33 \% ; \mathrm{p}=0.006)$ (see table).

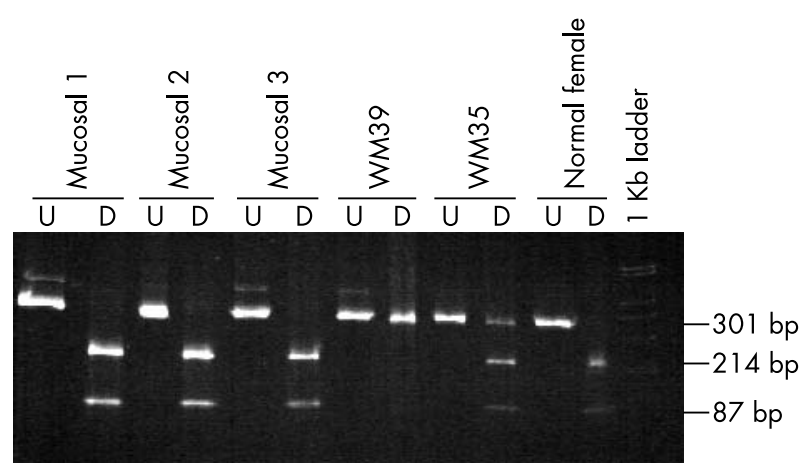

Figure 1 TspRI RLFP analysis of the V599E BRAF mutation. PCRamplified DNA from three mucosal melanomas, the melanoma cell lines WM39 and WM35, and normal human female DNA were digested and analysed as described. None of the mucosal melanomas has a BRAF mutation; WM39 has one mutant BRAF allele and a subchromosomal deletion involving the other allele; WM35 has one mutant and one wildtype allele; the female DNA has two wild-type alleles. All PCR products are shown undigested (U) and digested (D). Restriction fragment sizes are as indicated.

\section{DISCUSSION}

In the present study, we did not identify any exon 15 BRAF mutations in 13 mucosal melanomas. This finding is in sharp contrast to the cumulative published rate of $33 \%$ in primary cutaneous malignant melanoma ${ }^{6-10}$ and thus represents a distinct genetic difference in melanomas arising from cutaneous $v$ mucosal sites. Exon 11 was not evaluated in this study as mutations in this region account for a very small percentage of total BRAF mutations in both cutaneous melanoma and cancers arising from non-sun-exposed tissues. $^{23}$ The lack of BRAF mutations identified in mucosal sites suggests that the prevalence of $B R A F$ mutations in melanoma varies depending upon the anatomical origin of the tumour, possibly in direct relation to the extent of sun exposure for the tissue of origin. However, we cannot exclude the possibility that an inherent feature of the tissue type of origin is the determinant of BRAF mutagenesis in melanoma. Further studies of mutation prevalence in different subtypes of cutaneous melanoma (superficial spreading, nodular, acral lentiginous, and lentigo maligna melanoma) may be informative in this regard, as the extent and type of sun exposure varies between these subtypes.

While the mechanism of BRAF mutagenesis in melanoma is unknown, a role for UV exposure must be considered. The major UV-generated DNA lesions, cyclobutane pyrimidine dimers and 6-4 photoproducts, lead to $\mathrm{C} / \mathrm{T}$ or $\mathrm{CC} / \mathrm{TT}$ transitions, not the commonly described $\mathrm{T} / \mathrm{A}$ transversion in $B R A F$. However, several additional minor photoproducts also are generated. The role of these compounds in UV mutagenesis is not well-studied, but they include thymine glycol, pyrimidine hydrate, 8,8-adenine dehydrate, and

Primary cutaneous melanomas analysed for $B R A F$ mutations

\begin{tabular}{lcc}
\hline Reference & $\begin{array}{l}\text { Primary cutaneous } \\
\text { melanomas studied }\end{array}$ & $\begin{array}{l}\text { Number (\%) with BRAF } \\
\text { mutation }\end{array}$ \\
\hline Dong et al & 28 & $7(25)$ \\
Uribe et ap & 25 & $13(52)$ \\
Pollock et $a{ }^{\beta}$ & 5 & $4(80)$ \\
Yazdi et $a P^{p}$ & 97 & $28(29)$ \\
Cruz et al & 10 & $2(20)$ \\
Total & 165 & $54(33 \%)$ \\
\hline
\end{tabular}


thymidylyl- $\left(3^{\prime}-5^{\prime}\right)$-deoxyadenosine. ${ }^{11}$ Of relevance to BRAF mutagenesis, production of thymidylyl-( $\left.3^{\prime}-5^{\prime}\right)$-deoxyadenosine has been associated with T/A transversions. ${ }^{11}$

In addition to generating DNA photoproducts, UV exposure can also lead to oxidative modification of DNA. To date, more than 30 different nucleotide modifications have been shown to be generated by oxidative damage (reviewed in Ohshima et $\left.a l^{5}\right)$. The most widely studied DNA oxidation product, 8-hydroxy-deoxyguanosine, mispairs with adenine, causing G/T transversions. Similarly, oxidative deamination of cytosine leads to mispairing with adenine, causing $\mathrm{C} / \mathrm{T}$ transitions. ${ }^{5}$ Thus while a direct role for UV-induced oxidation in BRAF mutagenesis has not been demonstrated, it is possible that an as yet undetermined oxidative lesion serves as a precursor for the BRAF T/A transversion. Of note, oxidative damage also occurs in the context of inflammation, which is a component of UV-induced sunburn. The detection of BRAF mutations in several additional tumour types potentially etiologically linked to inflammatory processespapillary thyroid cancer with Hashimoto's thyroiditis, ${ }^{12-14}$ pancreatic cancer with chronic pancreatitis, ${ }^{15-17}$ and ovarian cancer ${ }^{18}$ with cyclic, ovulation-induced inflammation-raises the possibility that inflammation-associated oxidative changes play a role in the genesis of $B R A F$ mutations.

Once a BRAF mutation is generated, UV exposure might also promote melanocytic tumour progression. BRAF is a component of the MAPK signalling pathway, with activation of BRAF leading to increased levels of phosphorylated ERK (reviewed in Smalley ${ }^{19}$ ). Depending upon the cellular context and level of activity, ERK activation may lead to cell proliferation, differentiation, or apoptosis. ${ }^{20}$ In normal melanocytes, UV-induced activation of MAPK induces differentiation through $\alpha$-MSH/MC1R-mediated increases in cAMP that directly or indirectly induce tyrosinase transcription. ${ }^{4}{ }^{19}$ In melanoma, however, constitutive ERK activation provides proliferative signals and inhibits differentiation. In support of this, dominant negative RAS mutations, ERK mutations, and MEK inhibitors lead to differentiation. ${ }^{19}$ Thus it is possible that in addition to inducing mutations, UV irradiation provokes a stronger proliferative response in melanocytes with an activating BRAF mutation than in neighbouring cells with wild-type $B R A F$, further promoting melanoma progression in UV-exposed sites.

In summary, these data demonstrate that exon 15 BRAF mutations are much less frequent in mucosal than cutaneous melanomas. Additional studies are needed to further assess the relationship between prevalence of this mutation in specific melanoma subtypes and ultraviolet exposure. Finally, the absence of BRAF mutations in mucosal melanoma suggests that mucosal lesions may not respond as well as cutaneous lesions in clinical trials of BRAF/MEK inhibitors.

\section{Authors' affiliations \\ R H Edwards, M R Ward, C A Medina, M S Brose, P Volpe, B L Weber, Abramson Family Cancer Research Institute, University of Pennsylvania, Philadelphia, PA, USA \\ H Wu, S R Lessin, Fox Chase Cancer Center, Philadelphia, PA, USA S Nussen-Lee, H M Haupt, A M Martin, Pennsylvania Hospital, Philadelphia, PA, USA \\ M Herlyn, The Wistar Institute, Philadelphia, PA, USA}

Research support was received from the National Cancer Institute, grant numbers 1K08CA93748 (to RHE) and P50CA093372 (to MH), the National Institute of Arthritis and Musculoskeletal and Skin Diseases, grant number K24 AR02102 (to SRL), and from the Abramson Family Cancer Research Institute (to BLW).
Conflict of interest: none declared.

Correspondence to: B L Weber, MD, Abramson Family Cancer Research Institute, University of Pennsylvania Medical Center, 514 BRB II/III, 421 Curie Boulevard, Philadelphia, PA 19104, USA; weberb@mail.med.upenn.edu

Revised version received 12 December 2003

Accepted for publication 12 December 2003

\section{REFERENCES}

1 Gilchrest BA, Eller MS, Geller AC, Yaar M. The pathogenesis of melanoma induced by ultraviolet radiation. N Engl J Med 1999;340(17):1341-8.

2 Davies H, Bignell GR, Cox C, Stephens P, Edkins S, Clegg S, Teague J, Woffendin H, Garnett MJ, Bottomley W, Davis N, Dicks E, Ewing R, Floyd Y, Gray K, Hall S, Hawes R, Hughes J, Kosmidou V, Menzies A, Mould C, Parker A, Stevens C, Watt S, Hooper S, Wilson R, Jayatilake H, Gusterson BA, Cooper C, Shipley J, Hargrave D, Pritchard-Jones K, Maitland N, Chenevix-Trench G, Riggins GJ, Bigner DD, Palmieri G, Cossu A, Flanagan A, Nicholson A, Ho JW, Leung SY, Yuen ST, Weber BL, Seigler HF, Darrow TL, Paterson H, Marais R, Marshall CJ, Wooster R, Stratton MR, Futreal PA. Mutations of the BRAF gene in human cancer. Nature 2002;417(6892):949-54.

3 Brose MS, Volpe P, Feldman M, Kumar M, Rishi I, Gerrero R, Einhorn E, Herlyn M, Minna J, Nicholson A, Roth JA, Albelda SM, Davies H, Cox C, Brignell G, Stephens P, Futreal PA, Wooster R, Stratton MR, Weber BL. BRAF and RAS mutations in human lung cancer and melanoma. Cancer Res 2002;62(23):6997-7000.

4 Jhappan C, Noonan FP, Merlino G. Ultraviolet radiation and cutaneous malignant melanoma. Oncogene 2003;22(20):3099-112.

5 Ohshima H, Tatemichi M, Sawa T. Chemical basis of inflammation-induced carcinogenesis. Arch Biochem Biophys 2003;417(1):3-11.

6 Dong J, Phelps RG, Qiao R, Yao S, Benard O, Ronai Z, Aaronson SA. BRAF oncogenic mutations correlate with progression rather than initiation of human melanoma. Cancer Res 2003;63(14):3883-5.

7 Uribe P, Wistuba II, Gonzalez S. BRAF mutation: a frequent event in benign, atypical, and malignant melanocytic lesions of the skin. Am J Dermatopathol 2003;25(5):365-70.

8 Pollock PM, Harper UL, Hansen KS, Yudt LM, Stark M, Robbins CM, Moses TY, Hostetter G, Wagner U, Kakareka J, Salem G, Pohida T, Heenan P, Duray P, Kallioniemi O, Hayward K, Trent JM, Meltzer PS. High frequency of BRAF mutations in nevi. Nat Genet 2003;33(1):19-20.

9 Yazdi AS, Palmedo G, Flaig M, Puchta U, Rechwerth A, Rütten A, Mentzel T, Hügel $H$, Hantschke M, Schmid-Wendtner M-H, Kutzner H, Sander CA. Mutations of the BRAF gene in benign and malignant melanocytic lesion. $J$ Invest Dermatol 2003;121:1160-62.

10 Cruz F 3rd, Rubin BP, Wilson D, Town A, Schroeder A, Haley A, Bainbridge T, Heinrich MC, Corless CL. Absence of BRAF and NRAS mutations in uveal melanoma. Cancer Res 2003:63(18):5761-6.

11 Otoshi E, Yagi T, Mori T, Matsunaga T, Nikaido O, Kim S-T, Hitomi K, Ikenaga $M$, Todo $T$. Respective roles of cyclobutane pyrimidine dimers, (6-4)photoproducts, and minor photoproducts in ultraviolet mutagenesis of repair-deficient xeroderma pigmentosum A cells. Cancer Res 2000;60(6):1729-35

12 Xu X, Quiros RM, Gattuso P, Ain KB, Prinz RA. High prevalence of BRAF gene mutation in papillary thyroid carcinomas and thyroid tumor cell lines. Cancer Res 2003:63(15):4561-7

13 Kimura ET, Nikiforova MN, Zhu Z, Knauf JA, Nikiforov YE, Fagin JA. High prevalence of BRAF mutations in thyroid cancer: genetic evidence for constitutive activation of the RET/PTC-RAS-BRAF signaling pathway in papillary thyroid carcinoma. Cancer Res 2003;63(7):1454-7.

14 Liu LH, Bakhos R, Wojcik EM. Concomitant papillary thyroid carcinoma and Hashimoto's thyroiditis. Semin Diagn Pathol 2001;18(2):99-103.

15 Ishimura N, Yamasawa K, Karim Rumi MA, Kadowaki Y, Ishihara S, Amano $Y$, Nio $Y$, Higami T, Kinoshita Y. BRAF and K-ras gene mutations in human pancreatic cancers. Cancer Lett 2003;199(2): 169-73.

16 Calhoun ES, Jones JB, Ashfaq R, Adsay V, Baker SJ, Valentine V, Hempen PM, Hilgers W, Yeo CJ, Hruban RH, Kern SE. BRAF and FBXW7 (CDC4, FBW7, $A G O, S E L 10)$ mutations in distinct subsets of pancreatic cancer: potential therapeutic targets. Am J Pathol 2003;163(4):1255-60.

17 Hall Pde L, Wilentz RE, de Klerk W, Bornman PP. Premalignant conditions of the pancreas. Pathology 2002;34(6):504-17.

18 Singer G, Oldt R 3rd, Cohen Y, Wang BG, Sidransky D, Kurman RJ, Shih leM. Mutations in BRAF and KRAS characterize the development of low-grade ovarian serous carcinoma. J Natl Cancer Inst 2003:95(6):484-6.

19 Smalley KS. A pivotal role for ERK in the oncogenic behaviour of malignant melanoma? Int J Cancer 2003; 104(5):527-32.

20 Satyamoorthy K, Li G, Gerrero MR, Brose MS, Volpe P, Weber BL, Van elle P, Elder DE, Helyn M. Constitutive mitogen-activated protein kinase activation in melanoma is mediated by both BRAF mutations and autocrine growth factor stimulation. Cancer Res 2003;63(4):756-9. 